\title{
PLANNING WITH NATURE: SUSTAINABLE URBAN PROTOTYPES FOR PORTUENSE DISTRICT IN ROME, ITALY
}

\author{
FRANCESCA SILVESTRINI, FABIOLA FRATINI \& ROBERTO MAGINI \\ Department of Civil, Building and Environmental Engineering, Sapienza University of Rome, Italy
}

\begin{abstract}
The objective of this study is to regenerate the Portuense district of Rome, in the southwest quadrant of the city, referring to nature-based solutions (NBS) coupled with sustainable solutions in rainwater management. The role of water, both as a resource and as an essential element of urban landscape, was considered. Nature-based solutions include several concepts or technologies ranging from blue-green infrastructure to water saving measures to sustainable rainwater drainage, and their use can be an important tool to mitigate the negative effects of climate change. To this end, high levels of integration between experts from different disciplines are necessary, specifically urban planners, water engineers and ecologists, and the involvement of land and water managers, planners and policy makers on all spatial scales is required. The design solutions in this work were developed following the United Nations 2030 Agenda for the Sustainable Development Goals (SDGs) and fitting the following models of city [1]: the Oasis City where NBS solutions improve the thermal well-being of the inhabitants reducing the heat island effect (environmental function); the City of Sponges to increase soil permeability and control rainwater flow making more sustainable the urban drainage system (environmental function); the City for People to improve the liveability and sociability of the spaces (social function). Based on these principles, three design solutions, called prototypes, have been developed: Pocket Park (environmental function), Main Avenue (social functions), Tiber Park (environmental and social functions). The biotope area factor, BAF index, was used here as the main measure to evaluate the effectiveness of the design solutions. The solutions proposed in each prototype can be repeated for all the interventions conceived in the "network of spaces" of the Portuense district. Keywords: sustainable urban planning, nature-based solutions, sustainable urban drainage, BAF index, environmental comfort, urban outdoor spaces, City for People, Oasis City model, Sponge City model.
\end{abstract}

\section{INTRODUCTION}

Urbanization and its adaptation to climate change are nowadays being discussed worldwide. It is important to address the resulting problems at all scales and certainly urban design has a key role: it can respond to the problems related to climate crisis mitigation and promote sustainable resource management [2], [3]. In regenerating the city and redesigning in the direction of an ecological transition, it is necessary to assume an integrated methodology of different disciplines operating on a nature-based principle. Public space is at the heart of the research proposals for the regeneration of cities. The liveability of spaces and their environmental quality can make a difference in the evolutionary process of cities towards sustainability [4]. Open spaces must be well designed, enjoyed by citizens, and meet environmental comfort requirements [5]. The comfort caused by good design is usually strongly linked to the use of natural elements. Only in the last 60 years it is understood that a balanced environment must contain all of the ingredients necessary for biological prosperity, social cooperation, and spiritual stimulation of humans [6]. These factors are addressed by ecology, one of the disciplines that led to the results of these studies. A project must be based on human perception and environmental needs, as well as their relationship. In this way, the quality of life of citizens is increased [7]-[9]. 
Within this context, water has a fundamental role as a determining element of the new paradigm of sustainable eco-city. This paradigm is based on the assumption that "urban waters are the lifeline of cities and focus of the movement towards more sustainable cities" [10]. This paradigm extends from the microscale of the "green" buildings to the macroscale of the eco-city and urban water catchment [11]. Environmental engineers and urban planners are developing water/rainwater/wastewater management concepts based on reuse and recycling, and on the importance of water as an element characterizing the urban landscape, which affects the overall well-being of the inhabitants

In this sense, the research was developed according to 2030 Agenda for Sustainable Development Goals (SDGs), adopted by all United Nations Member States in 2015 (Goals $3,6,11,13)[12]$. In the project it was considered important to increase the quality of urban spaces at the same time as adopting useful strategies to mitigate the effects of climate change. Three types of cities have been taken as a reference, in line with the design laboratory REBUS (REnovation of public Buildings and Urban Spaces), conceived by the Emilia-Romagna Region in 2015 [13]: the Oasis City, for the well-being of the inhabitants; the Sponge City to increase permeable soils and control rainwater flow; the City for People, for the liveability and sociability of spaces [1].

\section{STUDY AREA}

The selected area is Pian due Torri, more commonly known as Magliana. It is a fraction of the Portuense district, in the southwest quadrant of the city of Rome, Municipality XI of the City of Rome. The Portuense district is bordered to the east by the Tiber River, to the west by the axis of the Via Portuense and to the south by the A91, the Rome-Fiumicino freeway. The whole area is located seven meters below the Tiber embankment. In the past it was infested with mosquitoes and unhealthy due to the frequent floods of the Tiber. Between the sixties and seventies of the last century the area was intensively built up.

\section{METHODOLOGY AND MATERIALS}

The research project developed as a result of some questions that stimulated our curiosity and showed us how necessary it was to look for new solutions to today's problems in our cities. How can cities be rethought after the experience of the pandemic? Are cities a problem or can they be the solution? What role can the regeneration of public spaces play in view of the dual problem of the climate emergency and the health emergency? And finally, is it possible to rethink a transformation process that designs public spaces in such a way as to meet the needs of the contemporary city?

The methodology used to develop the project is articulated using the three city models proposed by REBUS Project [1] with the main objective of making the urban environment more resilient to the effects of the climate change, in particular to heat waves (City Oasis model) and the greater frequency of intense precipitation (Sponge City model), without forgetting to make the city more liveable for its inhabitants (City for People). The realization of these three city models is based on the use of nature-based solutions (NBS), sustainable drainage systems (SuDS), with the biotope area factor (BAF) index, as a measure of the effectiveness of the proposed design solution. The goodness of each solution was also evaluated by its ability to answer the inhabitants' psychological, social, and cultural requirements. A schematic of the methodology is represented in Fig. 1, where each of the three city models corresponds to an objective to be reached and the set of tools to be used. 


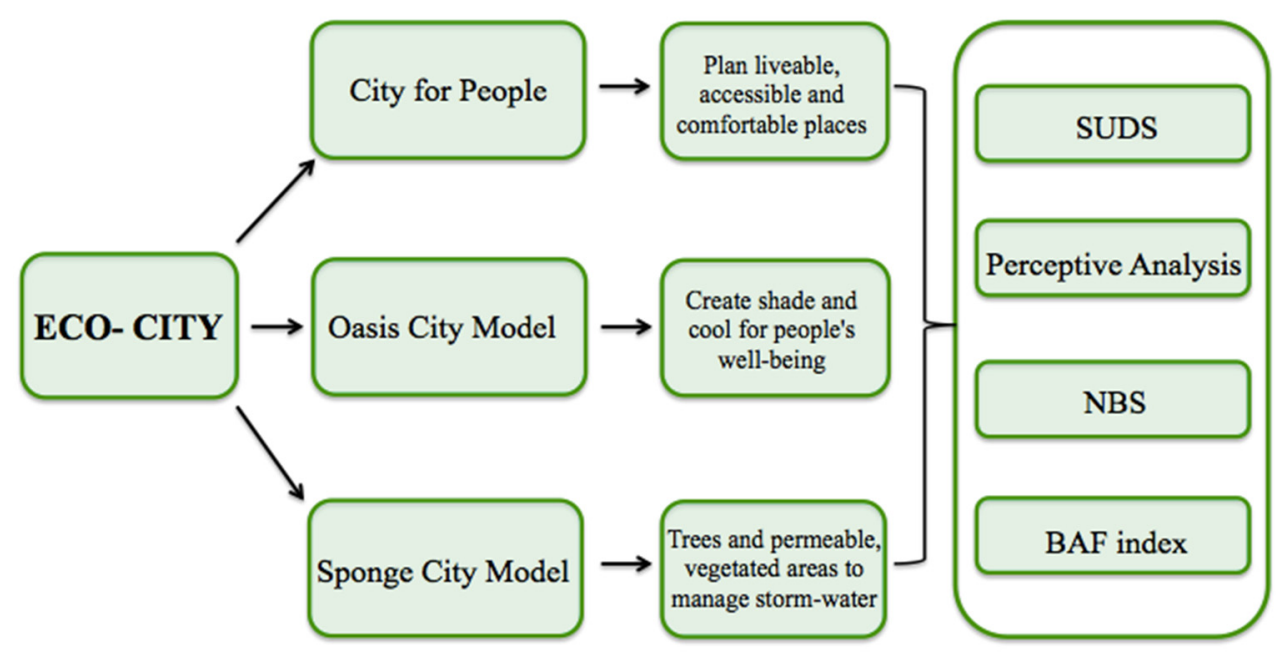

Figure 1: Outline of the methodology.

\subsection{City for People model}

The City for People model is about the liveability of public spaces. They are spaces in which inhabitants voluntarily decide to go and spend their time. It is essential that this kind of spaces are designed to be as accessible as possible and with wide space equipped for socializing. These aspects, integrated with others more related to environmental comfort, will allow the creation of public spaces with a high environmental quality. A more natural space, as stated by Gehl [14], is also more comfortable and attractive, and this greatly enhances its quality. In the project, to ensure a citizen-friendly city, the focus was supported by the methodology elaborated by Lynch [15]. The elements proposed by Lynch were selected to promote their enhancement and to make them the representative elements of the neighbourhood under research.

\subsection{Oasis City model}

In the Oasis City model the nature-based solutions allow the creation of thermal comfort zones to serve the inhabitants. In fact, cities can be places with higher temperatures than surrounding regions. This occurs because of the built environment that characterizes most urban lands. The goal is to mitigate the often dangerously high temperatures caused by climate change. The vegetated areas not only affect the climate of the area but also work simultaneously for the hydraulic safety, going to increase the area of permeable soil and the evapotranspiration and reducing rainwater velocity. The benefits can be evident when creating a real network capable of influencing the thermal and hydrological state of an area as large as the neighbourhood selected for the project. By reducing heat island effects, it will be possible to benefit from improved air and water quality, as well as increased comfort and human health.

\subsubsection{Nature-based solutions (NBS)}

Nature-based solutions can be considered as a term that encompasses different concepts or technologies ranging from blue-green infrastructures to natural water recovery measures, to 
ecosystem-based adaptation [16]-[18]. The NBS that have been considered for the neighbourhood concern a dense network of spaces and include interventions useful to the welfare, health, and safety of people. The tree species have been selected among those native and most capable of reducing pollutants and storing $\mathrm{CO}_{2}$. Among the planned actions, the most influential is the creation of a totally self-sufficient linear park: Tiber Park. All the solutions foreseen have been integrated with sustainable drainage systems useful to reduce the run-off of rainwater and better detailed in the paragraph of the Sponge City.

\subsection{Sponge City model}

The model of the Sponge City is the second model considered. Following the experience of the French eco-neighbourhoods and permeable squares, now spread out all over Northern Europe, we try to respond to the hydraulic fragility of the Portuense area, introducing small but significant changes. Interventions for the water run-off control and water recycle are proposed, namely: infiltration trenches, grass swales, storage tanks and phytoremediation ponds to laminate and purify water. Also, permeable and vegetated pavements of the open spaces find their place in the project furnishing an important contribution to make drainage more sustainable and to mitigate heat island effects [19]. In fact, impervious, smooth and maybe sometime steep pavements, can cause an extremely rapid runoff during storm events: high peak flow can be reached in short time and a large amount of sediment and pollutants can reach the underground pipes and rivers, causing large damage [20]. On the contrary permeable and vegetated surfaces can play an excellent role in environmental control [21]. Furthermore, the use of vegetation to replace horizontal paved surfaces, but also vertical ones, can be an attractive decorative method.

\subsubsection{Biotope area factor (BAF)}

BAF is an index first applied to the city of Berlin in 1994 as part of the "Pro Landscape Program". It measures the permeability of an area and evaluates urban planning solutions based on the ecosystem functionality of the built environment, as a function of ecological land use [22]-[24]. Soil sealing is one of the biggest problems found in cities today and is a reason for several natural disasters [25], [26]. Lately, our cities are much more frequently victims of floods or flooding and despite this, the urbanization process is continuing to expand and cover natural or semi-natural areas with asphalt and concrete [27]. Soil sealing is a very important fact and the well-being of both humans and ecosystem depend on it. Some examples among the benefits that soil gives us are carbon sequestration, microclimate regulation, biodiversity protection or food production [28], [29]. The index is often used, as in our case, to simulate an alternative mitigation scenario in a specific area of the city and enrich the debate on land consumption by giving support to sustainable urban planning [30]. The analysis using the BAF index was carried out, firstly, mapping the green areas of the Portuense neighbourhood, and then assuming to increase them in the next project phase. The BAF index ranges from 0 , that means completely impermeable surfaces, to 1 , complete permeable surfaces. It is calculated using the following equation:

$$
B A F=\frac{\sum_{i} w_{i} A_{i}}{\sum_{i} A_{i}}
$$

where $w_{i}$ is the weighting factor for the $i$-th sub-area and $A_{\mathrm{i}}$ the extension of each sub-area. The weighting factor was assigned a value according to the soil permeability feature (Table 1). 
Table 1: Type of soil and weighting factor for BAF evaluation.

\begin{tabular}{|l|c|}
\hline Surface type & Weighting factor $\boldsymbol{w}$ \\
\hline Sealed & 0 \\
\hline Partially sealed & 0.3 \\
\hline Vegetated but unconnected to the soil & 0.7 \\
\hline Vegetated connected to the soil & 1 \\
\hline
\end{tabular}

For the limited extensions of the study areas BAF index was evaluated manually from the technical cartography of the municipality of Rome. BAF index is equivalent to other indices used to evaluate soil permeability and useful for verifying hydraulic invariance in urban transformations [31]. Specifically, it can be compared with the RIE Index, introduced in 2004 within the Building Regulations of the Municipality of Bolzano, Italy. BAF Index, beyond its original function, has an important role both within the context of urban drainage, heat mitigation and amenity of the places.

\subsubsection{Sustainable drainage systems (SuDS).}

This project makes use of sustainable drainage solutions in regenerating the Portuense district, which, due to its position and its average altitude, is subject to the risk of flooding whose frequency is increasing due to climate change. We can define "sustainable" a drainage system that manages rain water runoff taking into account the water quantity control just to reduce the risk of flooding, water quality to limit pollution, biodiversity to favor wildlife and plants and guarantee the amenity of the places. Guidelines for sustainable drainage were published as early as 1992 with the title "Scope for Control of Urban Runoff" [32]. These techniques initially found diffusion in the UK but today they are everywhere essential in the design and management of drainage systems [33], [34]. SuDs solutions are crucial in achieving the Sponge City model. They can be used both in green areas, to retain water and infiltrate it slowly into the ground and in built-up areas, also favoring the retention and infiltration of rainwater. Each site is unique, so the appropriate drainage technique must be chosen and applied.

In particular, in this this project, solutions that favor infiltration, slow down runoff, retain and purify rain water have been considered (Fig. 2). They can be summarized as follows:

- fully permeable drainage solutions, namely: dry vegetated channels or grass swales, filtering wedges, filtering strips, tree-boxes;

- partially permeable drainage solutions, i.e.: public space/parking surfaces, unconnected vegetated surfaces;

- $\quad$ phyto remediation ponds;

- retention tanks, used also for recycling water.

\section{RESULTS}

Three main interventions called "prototype" have been conceived, since the intention can be repeated for all the interventions foreseen in the "network of spaces" planned within Portuense district.

\subsection{Prototype 1: Pocket Park}

For the first prototype project a strategic location of the district has been chosen, the Villa Bonelli station of the FL1 railway line. It was decided to reduce the imperviousness of the 


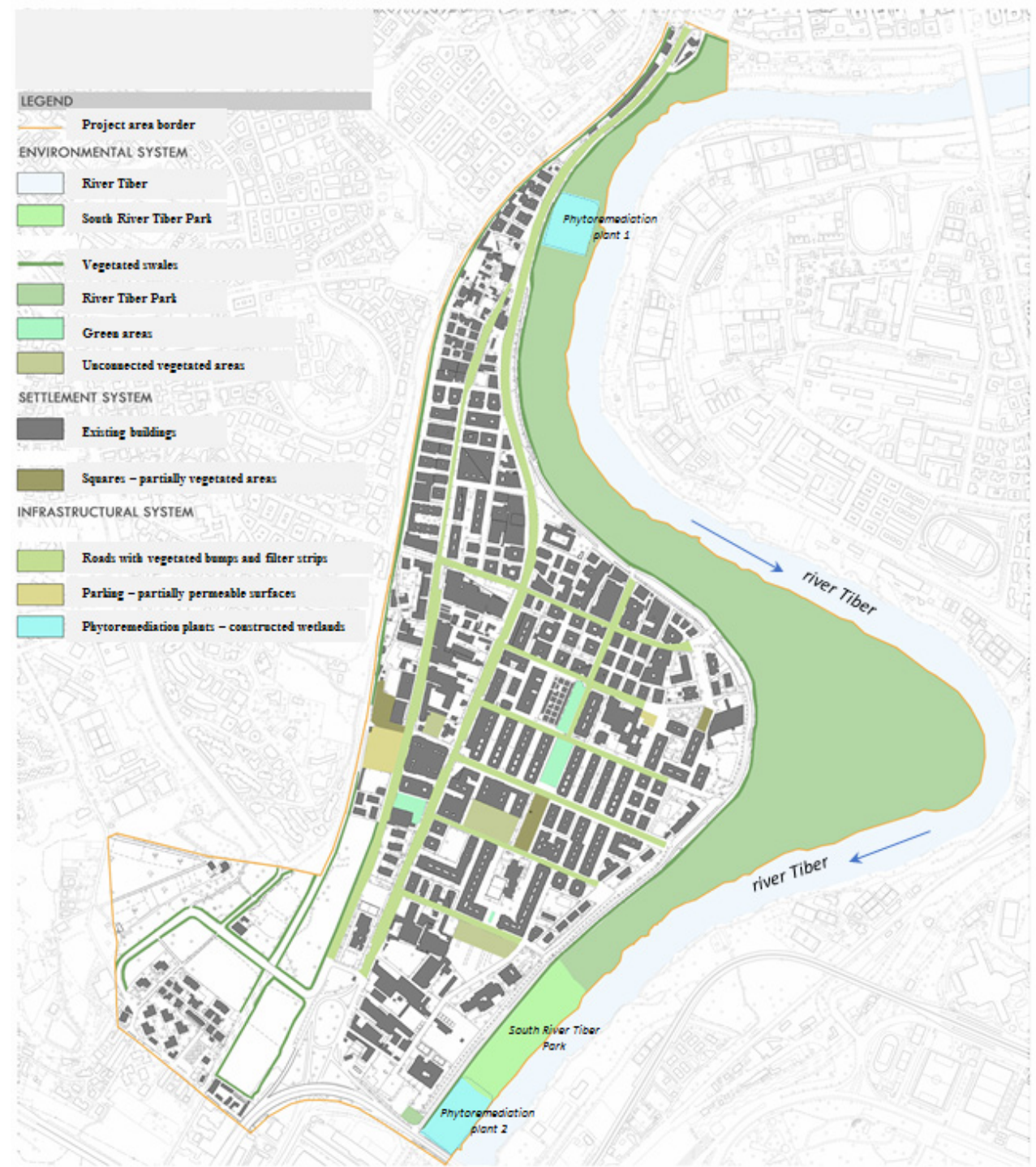

Figure 2: Map of the main design solutions.

train station and the adjacent parking area with a draining pavements. The whole area has been requalified with a wooden roof with seats for the terminus of bus line, the addition of a rest and refreshment area with equipped green areas and a short stop area for cars, with green areas of different use (Fig. 3).

For the area to regenerate, in front of the train station, a Pocket Park has been thought of. Its peculiarity is that it is located in a very busy place especially for the passage and it is above a public parking lot. The morphology has been designed to manage the flow of pedestrians coming from the Villa Bonelli station and from Via della Magliana: it has a 

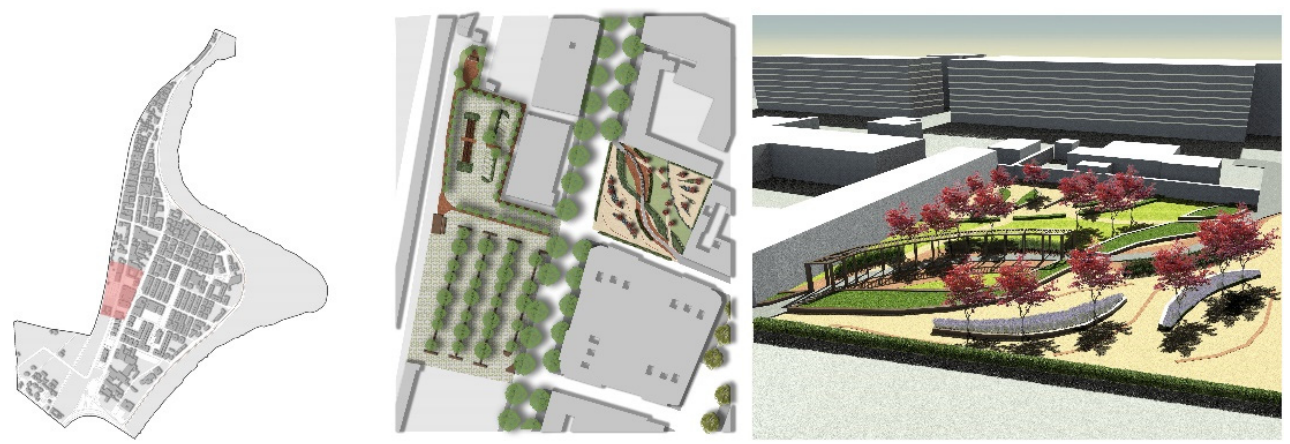

Figure 3: Prototype 1: localization, map and 3D view of Pocket Park.

central strip used for rapid passage that divides an area, more intimate and hidden, equipped with seats and used for rest and aggregation of citizens, and an area more exposed than the first, intended for both rest and transit. Because of its location on the public parking, the selection of vegetation has been rather constrained. Very small and high performance trees were chosen: Acer palmatum, to shade the seats and the paths; Ligustum coriaceum and Pittosporum tobira, which have high $\mathrm{CO}_{2}$ storage and $\mathrm{PM}_{10}$ abatement capacities, and were used for the flowerbeds dividing the Pocket Park from the street and for the internal flowerbeds; Lavandula and Glyceria maxima, used for the internal flowerbeds and having high pollution and rainwater absorption capacities. The project was able to achieve the target BAF index of 0.3 . The previously impervious areas of $9492.5 \mathrm{~m}^{2}$ are now partially sealed or even totally permeable areas. With regard to the factors of absorption of pollutants related to the plantings chosen we have: the maples will absorb 0.213 grams/tree/day of $\mathrm{NO}_{2}$ and $0.035 \mathrm{grams} /$ tree/ day of $\mathrm{PM}_{10}, \mathrm{CO}_{2}$ sequestered will be equal to 0.0010 tons/tree/year.

\subsection{Prototype 2: Main Avenue}

The second prototype project was carried out in the central core of the neighborhood. The designed avenue includes the current Via Lari and Viale Vicopisano. The area has an important social role, being the main place of aggregation for the inhabitants. The idea is to realize an avenue marked by three different consecutive flowerbeds. Each flowerbed has a particular function according to the needs given by its position and is strongly characterized by a different color and type of vegetation. Mainly, there are two paths, a main one and a secondary one that resume the trend of a hypothetical river with a sinuous path, because of the proximity to the neighborhood of the Tiber River.

The reference of this project was the linear park Superkilen in Copenhagen, realized between 2011 and 2012. It is a large open-air installation divided into three basic parts, developed on a strip of land over $750 \mathrm{~m}$ long. The first two parts are made with the same material but characterized by different identification colors and uses, while the third has a more traditional lawn arrangement (Fig. 4). The project totally converted the area from impervious to partially sealed or permeable going to meet the target BAF index. The project gave special attention to the livability of these new spaces created for citizens. The aspect of perceptual evaluation was fundamental to create 11,000 new square meters available to citizens. These spaces will accommodate dozens of new functions including children's playgrounds, sports equipment, performance areas, seating areas, etc. 


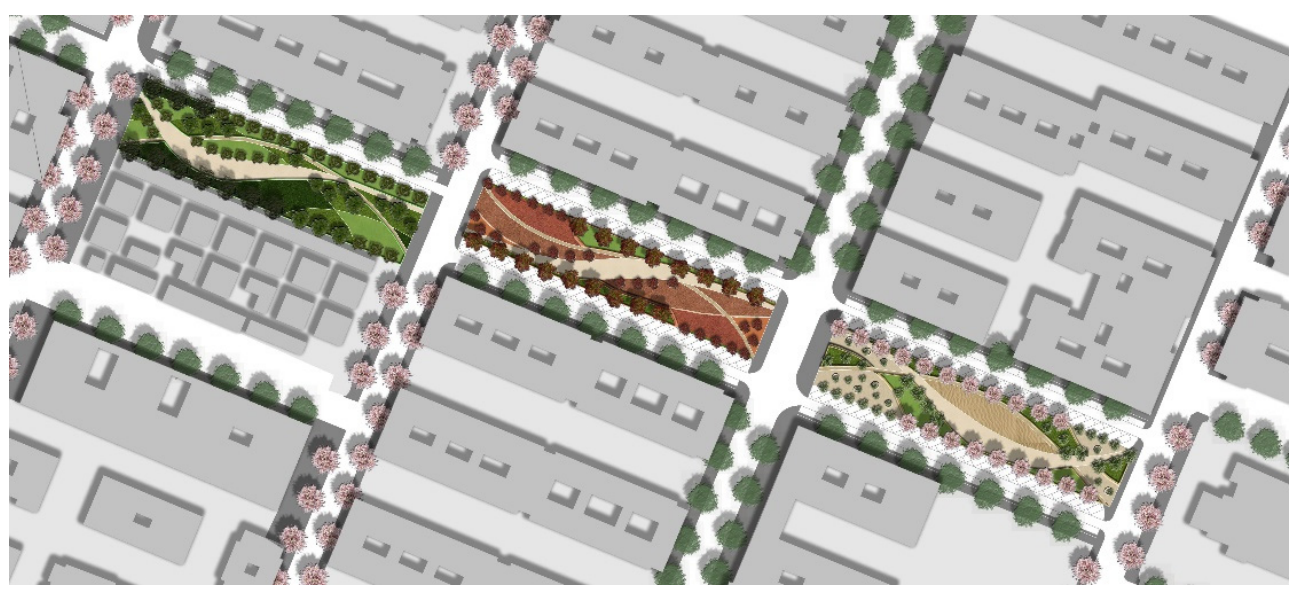

Figure 4: Prototype 2: Map of Main Avenue regeneration.

\subsection{Prototype 3: The Tiber Park}

The Tiber Park (Fig. 5) was designed in continuity with the park recently built in the southernmost part of the neighbourhood. The park as a whole can be flooded and will therefore protect the neighbourhood behind, from which a high embankment divides it. The park provides for the development within it of many functions, including a large central square as a space for aggregation of the inhabitants, a botanical garden for the increase and growth of biodiversity of the river, play areas for children and areas equipped for sports. The areas include spaces with both collective and individual functions, to allow the inhabitants to take care of their health in open spaces and enjoy alone or in company of the presence of natural elements.

Within the context of this prototype, to make the neighbourhood a part of a potential Sponge City, two phytoremediation plants were designed to purify rainwater drained by the collecting system. The water leaving these plants is collected in underground tanks from which it is taken by tank trucks and recycled for washing the streets and watering the green areas of the neighbourhood (Fig. 6). The plant species chosen for the phytoremediation plants are autochthonous species commonly used for constructed wetland in Italy: Schoenoplectus lacustris, Typha latifolia and Phragmites australis. In particular, each planting has a different threshold of root penetration and depending on the position in the tank, the most appropriate is planted (Fig. 7).

The park's output was accessibility, inclusion, and multi-functionality, in line with City for People goals. It is a rich, expanded public space that has been returned to citizens. Each function included in the park has been designed for a different age group of users, there are facilities for children from 2 years old and others for children from 6 years old, there are also sports facilities for all and walks on walkways and among the plants of the botanical garden that are also suitable for the older segment of the population. The filter area of 45,024 $\mathrm{m}^{2}$ inside the park has about 110 specimens of white poplar of different sizes and plays a key role in the air quality of the neighborhood. The filter area contributes to the absorption of : 553.84 tons/year of $\mathrm{CO}_{2}, 27.14$ grams/day of $\mathrm{PM}_{10}$ and 446.464 grams/day of $\mathrm{NO}_{2}$. 


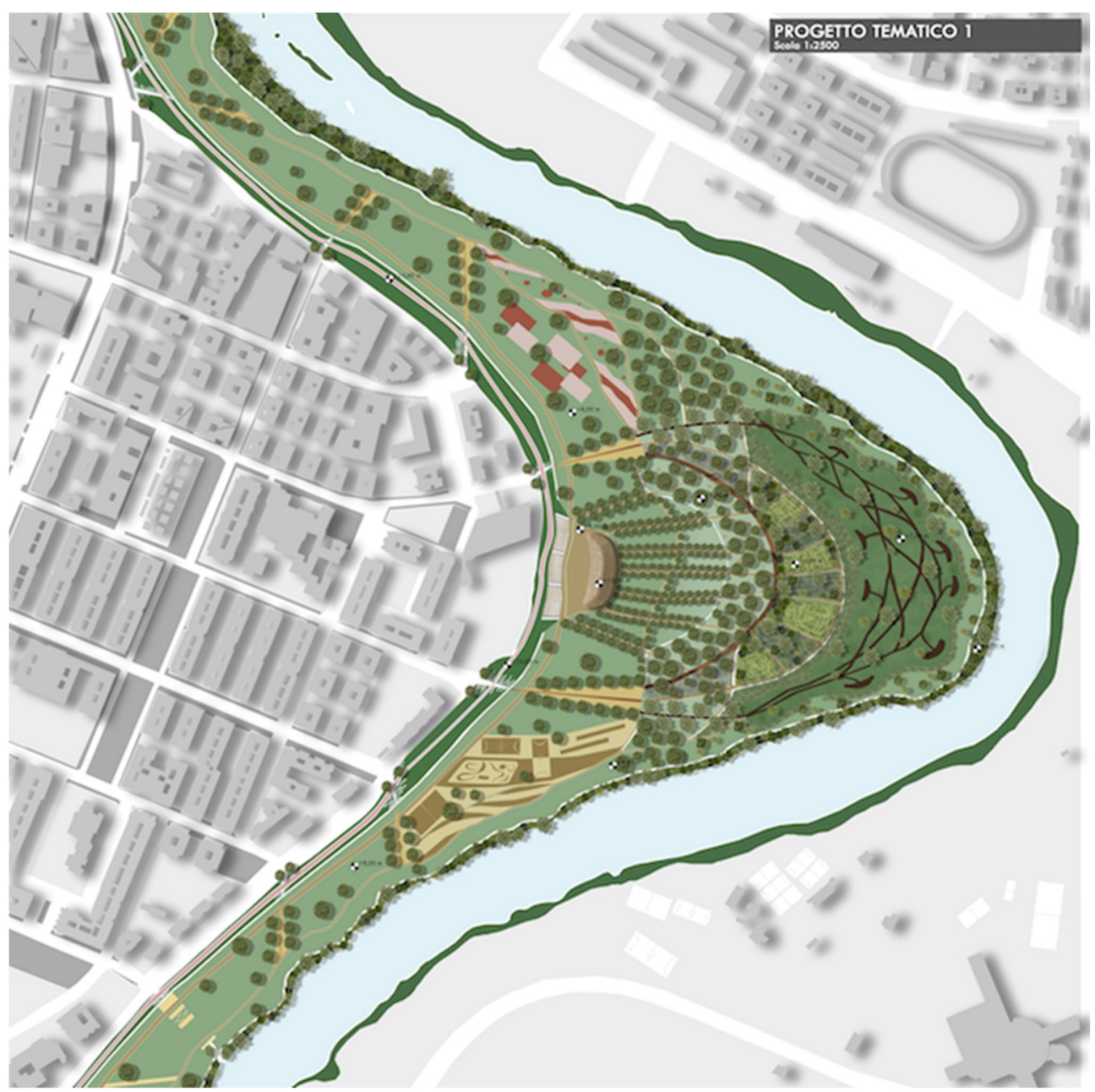

Figure 5: Prototype 3: Map of Tiber Park.

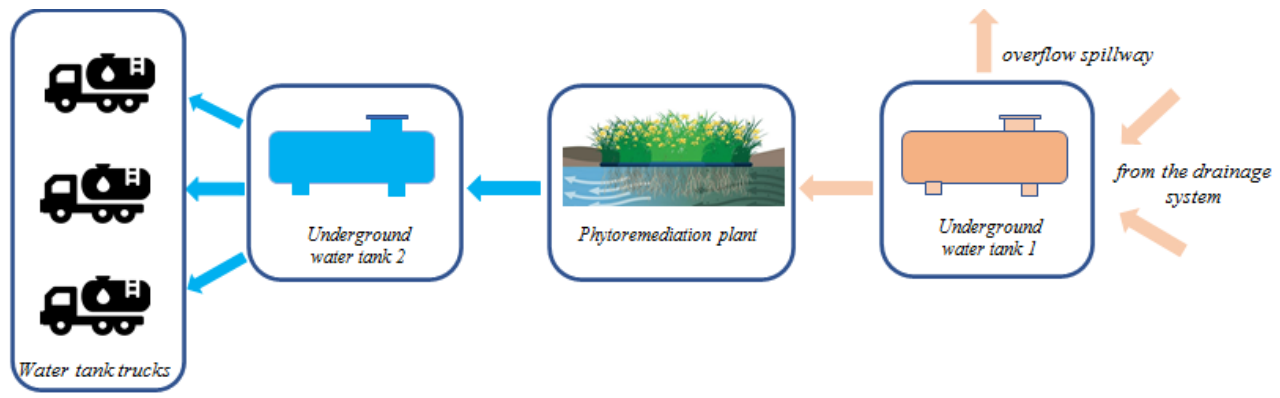

Figure 6: Prototype 3: Schematic of rainwater recycling system. 
Schoenoplectus lacustris

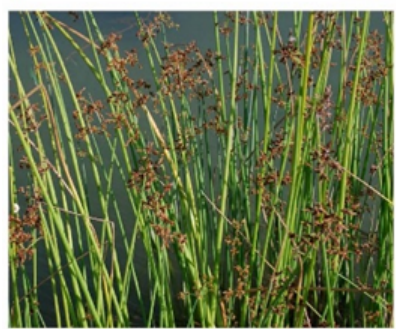

root penetration $90 \mathrm{~cm}$
Typha latifolia

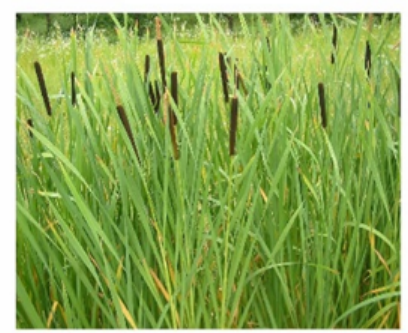

root penetration $40 \mathrm{~cm}$

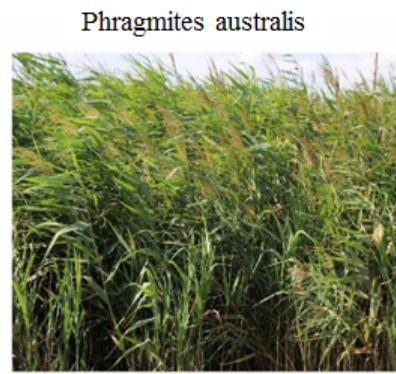

root penetration $70 \mathrm{~cm}$

Figure 7: Prototype 3: Plant species selected for phyto depuration.

\section{CONCLUSIONS}

In this work, we wanted to affirm the need to unify the skills related to different disciplines for a perfectly aware urban design. The importance of a multidisciplinary approach involving knowledge related to urban climatology, hydraulics, botany, psychology, sociology, and ecology was highlighted. In this context, the goodness of the overall project will have to be evaluated starting from the results of each type of investigation, through "intelligent" cognitive maps capable of establishing connections between the disciplines. Specifically, key indices for each specific discipline must be linked together with connections that represent their reciprocal relationships. The result will be obtained through an optimization process on the overall effects of every single intervention. The "prototypes" proposed by this study and the related "green network" that they create, constitute a first step in the formulation of this design methodology which aims to regenerate our cities by increasing their environmental sustainability and improving the quality of life of the inhabitants.

\section{REFERENCES}

[1] Ravanello, L., REBUS - Laboratorio sugli spazi pubblici per la mitigazione e l'adattamento ai cambiamenti climatici, 2018. Regione Emilia - Romagna.

https://territorio.regione.emilia-romagna.it/qualita-urbana/sostenibilita/rebus.

[2] Marry, S., Adaptation au Changement Climatique et Project Urbain, Parenthèses, Ademe, Éditions Parenthèses, 2020.

[3] EKLIPSE, Health activities, 2020.

http://www.eklipse-mechanism.eu/health_activities.

[4] Ravanello, L., Crisi climatica - Città per il clima, città per le persone, ARPAE CTR educazione alla sostenibilità, 2021. https://www.arpae.it/it/temi-ambientali/ educazione_alla_sostenibilita/azioni-educative/formazione/webinar/webinar-crisiclimatica-e-resilienza-urbana/7-luisa-ravanello-_-_-webinar-3-_-_-28-01-2021.pdf.

[5] Brown, R.D., Design with Microclimate: The Secret to Comfortable Outdoor Space, Island Press, 2010.

[6] McHarg, I., Design with Nature, The Natural History Press, 1969.

[7] Nikolopoulou, M. \& Steemers, K., Thermal comfort and psychological adaptation as a guide for designing urban spaces. Energy and Buildings, 35, p. 95, 2003.

[8] Nikolopoulou, M. \& Lykoudis, S., Thermal comfort in outdoor urban spaces: Analysis across different European Countries. Building and Environment, 41(11), p. 1455, 2006. 
[9] Givoni, B. et al., Outdoor comfort research issues. Energy and Buildings, 35(1), p. 77, 2003.

[10] Novotny, V. \& Novotny E.V., Water centric cities of the future: Towards macro scale assessment of sustainability. Water Sensitive Communities, eds C. Howe \& C. Mitchell, IWA Publishing, 2011.

[11] Novotny, V., Sustainable urban water management. Water and Urban Development Paradigms, eds J. Feyen, K. Shannon \& M. Neville, p. 19, CRC Press, 2008.

[12] United Nations, Sustainable Development Goals, 2019. http://www.un.org/ sustainabledevelopment/sustainable-development-goals/.

[13] https://territorio.regione.emilia-romagna.it/urbanistica/corsi-formazione/rebuslaboratorio-rigeneraz-urbana-cambiam-climatici.

[14] Gehl, J., Cities for People, Island Press, 2013.

[15] Lynch, K., The Image of the City, MIT Press, 1964.

[16] European Commission, Nature-Based Solutions. State of the Art in EU, Funded Projects. Directorate-General for Research and Innovation. European Commission, 2020.

[17] Nesshover, C. et al., The science, policy and practice of nature-based solutions: An interdisciplinary perspective. Science of the Total Environment, 579, p. 1215, 2017.

[18] Pauleit, S. et al., Advancing urban green infrastructure in Europe: Outcomes and reflections from the GREEN SURGE project. Urban Forestry and Urban Greening, 40, p. 4, 2019.

[19] Cambridge Systematics, Inc, Cool pavement report: EPA cool pavements study task 5. U.S. Environmental Protection Agency, 2005.

[20] Dessì, V., Progettare il Comfort Urbano: Soluzioni per Un'integrazione tra Società e Territorio, Esselibri, AS15, 2007.

[21] European Commission, Soil sailing. Science for environment policy. In-depth reports, 2012.

[22] Ahern, J., Green infrastructure for cities: The spatial dimension. Cities of the Future: Towards Integrated Sustainable Water and Landscape Management, eds V. Novotny \& P. Brown, IWA Publishing, p. 267, 2007.

[23] Keeley, M., The green area ratio: An urban site sustainability metric. Journal of Environmental Planning and Management, 54, p. 937, 2011.

[24] Becker, G. \& Mohren, R., The Biotope Area Factor as an Ecological Parameter, Landschaft, Planen \& Bauen, 1990.

[25] Prokop, G., Jobstmann, H. \& Schonbauer, A., Report on best practices for limiting soil sealing and mitigating its effects. European Commission, 2011.

[26] Naumann, S. et al., Land-take and soil sealing: Drivers, trends and policy (legal) instruments: Insights from European cities. International Yearbook of Soil Law and Policy, 2018.

[27] Artmann, M. \& Breuste, J., Cities built for and by residents: Soil sealing management in the eyes of urban dwellers in Germany. Journal of Urban Planning and Development, 141(3), 2015.

[28] Gardi, C., Urban Expansion, Land Cover and Soil Ecosystem Services, 1st ed., Routledge: New York, 2017.

[29] Wessolek, G., Sealing of soils. Urban Ecology: An International Perspective on the Interaction Between Humans and Nature, eds J. Marzluff et al., Springer, 2008.

[30] Peroni, et al., Biotope area factor: An ecological urban index to geovisualize soil sealing in Padua, Italy. Sustainability, 12(1), p. 150, 2020. 
[31] Botticelli, M., Guercio, R., Magini, R. \& Napoli, R., A physically based approach for evaluating the hydraulic invariance in urban transformations. Int. Journal of Safety and Security Engineering, 8(4), p. 536, 2018.

[32] CIRIA, Sustainable urban drainage systems: Best practice manual for England, Scotland, Wales and Northern Ireland. CIRIA Report No. CR086A, 2001.

[33] Fletcher, T. et al., SUDS, LID, BMPs, WSUD and more: The evolution and application of terminology surrounding urban drainage. Urban Water Journal, 15(7), p. 525, 2014.

[34] CIRIA, The SUDS manual. CIRIA Report No. C697, 2007. 